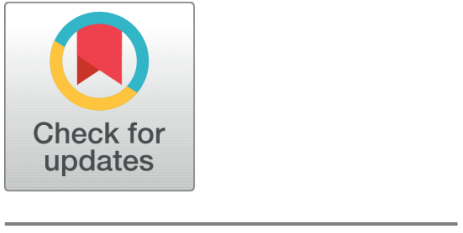

open access

Received: 23.03.2021

Accepted: 21.04 .2021

Published: 30.04 .2021

Citation: Tyagi P (2021) Writing Mathematical Theorems: Towards an Innovative Pedagogy. Indian Journal of Science and Technology 14(15): 1205-1211. https://doi.org/ 10.17485/IJST/v14i15.452

* Corresponding author.

Tel: +919810726750

pankajtyagi@cic.du.ac.in

Funding: None

Competing Interests: None

Copyright: @ 2021 Tyagi. This is an open access article distributed under the terms of the Creative Commons Attribution License, which permits unrestricted use, distribution, and reproduction in any medium, provided the original author and source are credited.

Published By Indian Society for Education and Environment (iSee)

ISSN

Print: 0974-6846

Electronic: 0974-5645

\section{Writing Mathematical Theorems: Towards an Innovative Pedagogy}

\author{
Pankaj Tyagi ${ }^{1 *}$ \\ 1 Cluster Innovation Centre, University of Delhi, Delhi, 110007, India. Tel.: +919810726750
}

\section{Abstract}

Objectives: Teaching mathematical theorems in Indian classroom settings usually focuses on explaining the statement of the theorem followed by methods of giving its proof. This hardly enables students to learn how to write a new theorem. Even teachers, at times, express their inability to write a new theorem. The objective of this article is to present a situational casestudy explaining the general processes involved to facilitate writing a new mathematical theorem. Methods: The methodology followed for coming up with a new mathematical theorem is based on careful observation of events around and recognizing patterns thereof. The emphasis is on summing up facts at different levels of observations, in order to evolve a concise theorem. Findings: From a small observation of the arrangements of the numbers on the keypads of a mobile phone or a calculator, a general mathematical theorem is evolved. This is an example for the pedagogy to be followed for writing a mathematical theorem, which can be useful both for the teachers and the students to self-educate themselves in new situations and casestudies. Novelty: This article formulates an innovative pedagogy using the mathematical concepts of subtraction, addition, divisibility, pattern recognition and generalization \& randomization of event to evolve a mathematical theorem. The transformation in statement of the theorem with addition of more and more facts leading to its newer versions is the main feature of this article.

Keywords: Mathematics Education; Mathematical Theorem; Innovative Pedagogy; Pattern recognition; Teaching Methods

\section{Introduction}

Pythagoras Theorem which states that in a right-angle triangle the square of its hypotenuse is always equal to the sum of the squares of the other two sides is one of the most elegant and simple worded theorems. From school days, we come across many mathematical theorems, which fascinate mathematics lovers, and are also taught how to prove these mathematical theorems. However, the one thing that is missing in our pedagogy is to teach how to write a new theorem. This may be the reason the people often complained that only a very few theorems are attributed to Indian mathematicians or scientists. 
In our education system, one can become a teacher after obtaining a graduation or a postgraduation degree in a particular subject and having a compulsory bachelor's or master's degrees in the field of Education. However, the responsibility of combining the art of teaching acquired during B.Ed. or M. Ed. and the knowledge of the subject acquired during graduation or postgraduation is purely lies on the concerned person. Even then, there is no doubt that teachers of our teachers were one of the best in the profession and our teachers mostly try to follow the pedagogy of their teachers in transferring knowledge to the students as teachers. However, for teaching something new, like how to write a new mathematical theorem, one has to change the ways of teaching from our ways of learning. If our teachers continued to teach our students by the methods invented long ago, we cannot bring the newness in the system. The need of the hour is to inculcate innovation in our pedagogical practices. In other words, we have to innovate the ways of teaching for simplified learning and to motivate our students for adopting these newer methods of learning.

In educational context, the innovations associated with methods of teaching are termed as pedagogical innovations. Each individual teacher can play an important role in it by innovating at least one method of teaching a concept or a topic of his or her choices. It can even be a slight alteration in existing methods of teaching. This method will be termed as innovative if it has more impact on student's learning in terms of his understanding the concepts or applying the concepts to explain the related facts. For this, one does not have to go through tedious methods of research and development. This can be easily done by the teachers themselves from his or her own experiences or through open discussions with peers and students.

There are many articles ${ }^{(1-5)}$ which focus on innovative ways to teach mathematics in schools. The main focus of these studies is on finding shortcomings in ongoing practices and use of technology to make them more effective. However, these studies lack in suggesting alternate ways of teaching specifically topic wise. In the article ${ }^{(1)}$,it is recommended that the teaching process should be interesting to attract students by adopting creativity in teaching strategies, but they do not provide examples from daily life taking into account the surroundings of the learner. The studies ${ }^{(2-5)}$ recommend different innovative methods and approaches for learning, like building students' hard and soft skills through innovative teaching approaches to mathematics, employing pretest and post-test experimental designs to analyze the contribution of innovative teaching, use of smart gadgets for different tasks like teaching, designing question papers, assessment of student, feedback and research methodology. They too discuss constraints to implementing new approaches in mathematics teaching and the need for such changes. However, none of these articles focuses on developing innovative methods topic wise. The studies related to innovative teaching methods and learning strategies ${ }^{(6-9)}$ emphasis the use of interactive ICT based teaching-learning methods, encourages hybrid teaching which include e-learning, suggests the ways of taking students out of the classroom through technological upgradation like smart classrooms, mobile learning, advocate the use of social platforms like podcast, screencast, blogging, virtual learning platforms like moodle etc. These all are methods of assisting the existing teaching practices. For innovative teaching newer ways are essential. In the article ${ }^{(10)}$, authors recommend the use of instruction of mathematical concepts through analogical reasoning to modify the misconceptions and difficulties of mathematical problems for students. However, there is lack of research papers to suggest pedagogical ways for use of concepts and drawing inferences from them to generate new knowledge. In one of our earlier work ${ }^{(11)}$, we have highlighted the importance of creating teaching human resource which is subject specific. For example, University of Delhi and Jamia Millia Islamia jointly in 2012 started Meta University concept based Masters' degree program in Mathematics Education, which is India's first subject specific course in mathematics domain. This type of courses provides a platform to the budding teachers to practice and invent the innovative methods of teaching mathematics at school level. Many examples are given in the article coming out of innovative pedagogy implementation during the course. Other articles ${ }^{(12,13)}$, demonstrate the use of mathematical concept by students in designing mathematical kits to assist children with autism and the ways of triggering innovative output by undergraduate students using pedagogy of hands on learning. Various example given in these article are testimony to it that innovative methods of teaching and learning are helpful in assisting independent thinking in learners and it encourages them to apply the knowledge towards solving the real world problems.

In the present article, it is attempted to innovate a pedagogy for writing mathematical theorem from small observations around us. Emphasis is on importance of careful observations, recognition of patterns in numbers, collation of the observed facts, acquiring newer facts and integration of these facts with earlier observations to arrive at a final version of the theorem. The findings are also interpreted with reference to existing pedagogical practices. The article provides an insight to the learner of the complete process of writing a theorem from observed facts and depicts the effectiveness of a little altering of existing pedagogies innovatively to make the learner more empowered.

\section{Writing a Mathematical Theorem: Evolving a Pedagogy}

Many things around us have particular forms and patterns. Most of the time we ignore them, however, sometime they catch our attention. If some observable patterns appear different to you, your interest in it grows. For example, generally, numbers 1 to 9 are arranged in 3 X 3 matrix form on keypads of a mobile phone or a calculator as shown in Fig1. 

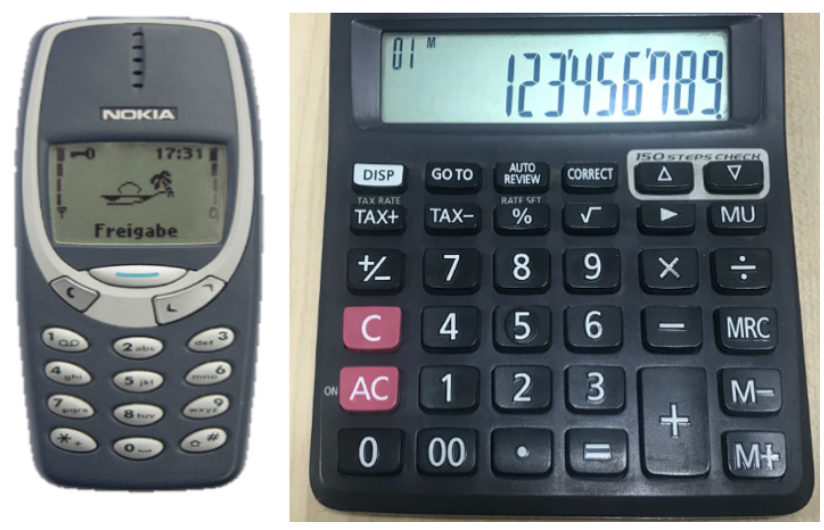

Fig 1. Keypads of a mobile or a calculator

Did you ever wonder why these numbers are arranged on keypads like this? Pondering over this question, lets explore it by playing with these numbers arranged in this particular fashion.

As these numbers are arranged in $3 \times 3$ matrix form with 3 rows and 3 columns. First, lets carried out following subtraction with respect to rows:

- Subtraction of numbers with 3 digits

$$
\begin{aligned}
& 321-123=198 \\
& 654-456=198 \\
& 987-789=198
\end{aligned}
$$

Note, here first row has digits 1, 2 and 3, so we have subtracted 123 from 321. i.e. first we have written a bigger number formed by three digits present sequentially in a row and then subtracted from it a number formed by reversing the order of digits.

The subtraction related to each row has resulted in same number. It's amazing to see this result.

As numbers here are of three digits occurring in sequential manner, it encouraged us to play more with such numbers of more digits. Look at the following results:

- Subtraction of numbers with 4 digits arranged sequentially:

$$
\begin{aligned}
& 4321-1234=3087 \\
& 5432-2345=3087 \\
& 6543-3456=3087 \\
& 9876-6789=3087
\end{aligned}
$$

- Subtraction of numbers with 6 digits arranged sequentially:

$$
\begin{aligned}
& 654321-123456=530865 \\
& 987654-456789=530865
\end{aligned}
$$


- Subtraction of numbers with 9 digits arranged sequentially:

$$
\begin{aligned}
& 987654321-123456789=864197532 \\
& 876543210-012345678=864197532
\end{aligned}
$$

- Subtraction of numbers with 2 digits arranged sequentially:

$$
\begin{aligned}
& 98-89=9,87-78=9, \quad 76-67=9 \\
& 54-45=9,21-12=9, \quad 10-01=9
\end{aligned}
$$

Do you observe any pattern in subtraction carried out so far? A careful observation of subtractions from facts (1) to (5) shows that if one converts the result of all these outputs to a single digit by adding up the numbers, they result into number 9 as shown below:

$$
\begin{aligned}
& 198 \Longrightarrow 1+9+8=18 \Longrightarrow 1+8=9 \\
& 3087 \Longrightarrow 3+0+8+7=18 \Longrightarrow 1+8=9 \\
& 530865 \Longrightarrow 5+3+0+8+6+5=27 \Longrightarrow 2+7=9 \\
& 864197532 \Longrightarrow 8+6+4+1+9+7+5+3+2=45 \Longrightarrow 4+5=9
\end{aligned}
$$

It means the output of these subtractions is always divisible by number nine. All such subtractions of numbers with digits 2 to 10 will give same result.

As a student or teacher, can we write a theorem summarizing all the above subtraction observations? It will be something like this:

Theorem (Version 1): "Subtracting a number of any number of digits (minimum two, maximum ten) formed by continuous sequence of decimal numbers $(0,1,2,3,4,5,6,7,8,9)$ from a number obtained by writing it in reverse order results in a number that is always divisible by number nine."

Writing a mathematical theorem for the first time starting from a pattern of digits on a mobile phone keypad is a real fun. This encouraged us to play more with these numbers arranged on keypads of mobile phone or calculators.

Next, lets carried out similar subtraction with respect to columns. It resulted in subtraction of following 3-digit numbers:

$$
\begin{aligned}
& 741-147=594 \\
& 852-258=594 \\
& 963-369=594
\end{aligned}
$$

Amazing, the output of these subtractions is also divisible by number nine. A careful observation reveals that these numbers are formed by leaving 2-decimal numbers between the adjacent digits. i.e. number 147 is formed by leaving digits 2 and 3 between 1 and 4 and by leaving digits 5 and 6 between 4 and 7 .

On similar lines, let's see the subtraction of numbers formed by leaving 3-decimal numbers between the adjacent digits.

$$
\begin{aligned}
& 951-159=792 \\
& 840-084=792
\end{aligned}
$$

The output of these subtractions is also divisible by number nine. 
Given below is a subtraction of numbers of 3, 4 and 5 digits formed by leaving 1-decimal number between the adjacent digits.

$$
\begin{aligned}
& 531-135=396 \\
& 8642-2468=5994 \\
& 97531-13579=83952
\end{aligned}
$$

The outputs of all these subtractions are also divisible by number nine.

Can we now write version 2 of above stated theorem combining all observed facts from (1) to (8)?

Before that lets do one more subtraction.

Write your mobile number and subtract reverse of it from the mobile number. For any dummy mobile number, it will be like this:

$$
9810726750-0576270189=9234456561
$$

Here too, one can see that

$$
9234456561 \Longrightarrow 9+2+3+4+4+5+6+5+6+1=45 \Longrightarrow 4+5=9
$$

Can we now write theorem's version 2 combining all observed facts from (1) to (9)?

It will be something like this:

Theorem (Version 2): "Subtracting a number of any number of digits from a number obtained by writing it in reverse order results in a number that is always divisible by number nine."

Can we improve our theorem by adding more facts to it? Let's play more with the subtractions of these numbers:

Carefully see the following subtractions:

$$
\begin{aligned}
& 951-159=792 \\
& 951-519=432 \\
& 951-915=036 \\
& 519-159=360 \\
& 97531-13579=83952 \\
& 97531-57913=39618 \\
& 97531-75139=22392 \\
& 9810726750-0576270189=9234456561 \\
& 9810726750-5677219800=4133506950 \\
& 8970162507-5677219800=3292942707
\end{aligned}
$$

Note, here all the numbers are randomly taken and the number that is being subtracted have similar digits as in chosen number but in different arrangements. Interestingly, the outputs of all these subtractions are also divisible by number nine.

Can we now write a final version of theorem combining all observed facts from (1) to (10)?

It will be something like this:

Pankaj's Theorem: "Subtracting a smaller number from a bigger number when both numbers have similar digits but with different arrangements results in a number that is always divisible by number nine."

The final version of theorem here has been termed as Pankaj's Theorem to give it a name to make it more realistic to the readers. 
One can easily verify this theorem by taking any arbitrary number of any number of digits. Pankajs Theorem is in fact can be treated as a theorem because it is being written based on various observed facts and it correctly summarizes all the observed facts in generalized form.

\section{Discussion}

If as a teacher, one state Pankaj's Theorem in a class room and ask students to verify it, they all will do it happily. As a matter of fact, the author actually did this exercise with more than 50 teachers and 200 students during the mentoring sessions under the project "Establishing Process Based Identification and Mentoring Practices for Potentially Gifted Children in Science and Mathematics (2014-2019)". It was a National level Project commissioned by the Office of Principal Scientific Advisor to the Government of India that focused on children having significant potentials in 'Science' and 'Mathematics'.

The objective of these sessions was not to write this theorem but to explain, both the teachers and students, the process that undergoes while writing a mathematical theorem. The detailed discussions with students and teachers have resulted in giving up the following important points:

Observations, interest and motivation: The role-played by observation of arrangements of numbers on keypads of mobile phone or that of calculator in creating the interest in playing with numbers is very important. It shows how things around us can motivate learners and led to new things (sometime may be not new to the world) for them. Once something interesting is being observed and learner start playing with them it leads to self-motivation for learning.

Pattern recognition: In this particular study, pattern recognition was the main factor that resulted in different versions of the theorem. It instigates the mind of observers to comprehend different situations and possibilities. For example, once you recognize a pattern in rows, immediately one looks for something similar in columns. Initially, one starts with smaller numbers then goes for larger numbers and so on. The important point is one shall try to explore various possibilities associated with observed facts.

Communication skills : One thing that prohibit most of the learners to write a theorem is communication skill. It is very important that one learn to summarize the facts at a very early stage. The moment one summarizes facts for the first time it gives you a confidence to continue with the started work.

Assessing progress: The transformation from one version of the theorem to the other shows that one is progressing in right direction. It is important to note that the version which one is calling final version may not be final. There may be more facts associated with it which one might not have observed so far. Someone latter can add the new facts to provide another latest updated version of the theorem.

Sense of achievement: To a learner nothing is more satisfying than having a sense of achievement of doing something new. Even though it happens too often that something which one have discovered by putting lots of efforts is already being discovered by someone else. One must understand that you can come to know this only through an extensive research only. Now-a-days search on internet has made it simpler for all of us to do this exercise. However, discovering something new for the first time (when you don't know that it exists) is always a big achievement and one shall feel happy about it. It truly exhibits your hidden talent.

Eliminating rote learning: The existing pedagogy of teaching mathematical theorems in our classrooms in which students are either asked or taught to prove it, the whole charm of the process of its discovery is lost in transit. This often leads to rote learning and do not result in motivating the students to become a self-learner. This surely need to be replaced by bringing innovative pedagogy. One must understand that innovative pedagogy can be used to taught only a few concepts and topics and not the whole syllabus because it is like a spice that bring taste to the food and not the food in itself.

\section{Conclusion}

The pedagogical innovations are very much-needed to enable the present learners to add new knowledge in near future. For this, the learners need to be trained in a manner that is different from the one that is followed presently. In this article, an innovative pedagogy is evolved with a situational case-study that enables a learner to write a mathematical theorem. All along this process, the importance of observation power, generation of interest, motivation for keep going, usefulness of pattern recognition, power of communication skill, ways of assessing progress and sense of achievements are demonstrated. It has been shown how summing up the facts in concise manner gives up shape to a statement that can be a mathematical theorem. The given case-study is an example of altering existing pedagogy innovatively to make learner more empowered. 


\section{References}

1) ALGANI YA. Innovative Ways to Teach Mathematics: Are they Employed in Schools? Journal of Computer and Education Research. 2019;7(14):496-514. Available from: https://dx.doi.org/10.18009/jcer.612199.

2) Rohaeti EE. Building Students' Hard and Soft Skills through Innovative Teaching Approaches to Mathematics. Journal of Southwest Jiaotong University. 2019;54(5):1-16. Available from: https://dx.doi.org/10.35741/issn.0258-2724.54.5.48.

3) Subramani PCN, Iyappan V. Innovative methods of Teaching and Learning. Journal of Applied and Advanced Research. 2018;3(S1):20-20. Available from: https://dx.doi.org/10.21839/jaar.2018.v3is1.161.

4) Abdulwahed M, Jaworski B, Crawford A. Innovative approaches to teaching mathematics in higher education: a review and critique. Loughborough University Journal contribution. 2012;17(2):49-68. Available from: https://hdl.handle.net/2134/11988.

5) Burton L, Haines C. Innovation in Teaching and Assessing Mathematics at University Level. Teaching in Higher Education. 1997;2(3):273-293. Available from: https://dx.doi.org/10.1080/1356215970020308.

6) Cunska A, Savicka I. Use of ICT Teaching-Learning Methods make School Math Blossom. Procedia - Social and Behavioral Sciences. 2012;69:1481-1488. Available from: https://dx.doi.org/10.1016/j.sbspro.2012.12.089.

7) and CMK. Advance Pedagogy: Innovative Methods of Teaching and Learning. International Journal of Information and Education Technology. 2015;5(11):869-872. Available from: https://dx.doi.org/10.7763/ijiet.2015.v5.629.

8) Samuel RS. E-learning, the next big name in education. Indian Journal of Science and Technology. 2011;4(3):173-176. Available from: https://dx.doi.org/ $10.17485 / \mathrm{ijst} / 2011 / \mathrm{v} 4 \mathrm{i} 3.13$.

9) Jaskyte K, Taylor H, Smariga R. Student and Faculty Perceptions of Innovative Teaching. Creativity Research Journal. 2009;21(1):111-116. Available from: https://dx.doi.org/10.1080/10400410802633673.

10) Amir-Mofidi S, Amiripour P, Bijan-zadeh MH. Instruction of mathematical concepts through analogical reasoning skills. Indian Journal of Science and Technology. 2012;5(6):1-7. doi:10.17485/ijst/2012/v5i6.12.

11) Sharma J, Tyagi P. Revival and Innovations in Mathematics Pedagogy: A Case Study. International Journal of Innovative Trends in Engineering. 2014;01:1416. Available from: https://www.ijite.com/citations/IJITE_1412_103.pdf.

12) Vashishth H, Sangeeta, Sharma J, Tyagi P. Designing of a Basic Mathematical Kit to Assist Mathematical Skill Development Among Children with Autism. International Journal of Advanced Research in Education \& Technology. 2016;3(3):153-158. Available from: http://ijaret.com/wp-content/themes/felicity/ issues/vol3issue3/himanshi.pdf.

13) Tyagi P. Triggering Innovative Output through Hands-On Learning at Undergraduate Level. International Journal of Interdisciplinary Research and Innovations. 2018;6(2):126-133. Available from: https://researchpublish.com//upload/book/Triggering\%20Innovative\%20Output-5639.pdf. 